\title{
Sobre o conceito de justiça: como estudantes o mobilizam na discussão de dilemas morais?'
}

\author{
Marcelo Andrade"
}

Luiz Câmara"

I- Agradecemos à equipe de bolsistas de iniciação científica, mestrandos e doutorandos que trabalharam nesta investigação: Anna Carolina Ayres, Eliana Palmeira, Giselma Sampaio, Monique Longo, Pâmela Cruz, Patrícia Campos, Pedro Teixeira, Raquel Pinho, Rodrigo Goulart e Viviane Amorim. Nosso agradecimento especial às professoras doutoras Helena Araújo (UERJ) e Cláudia Miranda (UNIRIO). A investigação contou com financiamento e bolsas de pesquisa do CNPq, da CAPES e da FAPERJ.

II- Pontifícia Universidade Católica do Rio de Janeiro, Rio de Janeiro, RJ, Brasil

Contatos: marcelo-andrade@puc-rio.br; luizccamara@hotmail.com

\section{Resumo}

Como estudantes de ensino médio mobilizam o conceito de justiça para lidar com dilemas morais? Buscou-se responder a essa questão de pesquisa a partir de dados empíricos e de algumas concepções de Habermas, em especial sobre o conceito de justiça procedimental e os critérios de igualdade, equidade, reciprocidade e de troca de papéis. 0 levantamento dos dados deu-se por meio da articulação de duas estratégias metodológicas: grupos focais e resolução de dilemas morais envolvendo questões de justiça e dignidade humana. Os grupos focais buscam entender a interação entre os sujeitos, ou seja, sua ênfase está na interlocução, o que se apresentou como fundamental para o estudo dos desafios cognitivos sobre o conceito de justiça numa perspectiva discursiva. Os dilemas morais, por sua vez, apresentam-se como situações hipotéticas e, nesta investigação, propiciaram um alto envolvimento dos sujeitos de pesquisa com a situação proposta. Dentre algumas conclusões possíveis, a pesquisa indica que os jovens não hesitam quando desafiados a se posicionarem em relação a problemas que envolvam suas crenças e convicções. Nesse sentido, a investigação reforça a pertinência de se utilizar o debate como uma estratégia para a prática pedagógica, de modo que, no espaço e no tempo da escola, as diversas visões de mundo e as características pessoais possam expressar-se.

\section{Palavras-chave}

Justiça - Habermas - Grupos focais - Dilemas morais Ensino médio. 


\section{On the concept of justice: how do students mobilize it in the discussion of moral dilemmas?}

Marcelo Andrade"

Luiz Câmara"

I- We would like to thank the team of scientific apprenticeship students, as well as master and doctoral students who have worked in this investigation: Anna Carolina Ayres, Eliana Palmeira, Giselma Sampaio, Monique Longo, Pâmela Cruz, Patrícia Campos, Pedro Teixeira, Raquel Pinho, Rodrigo Goulart and Viviane Amorim. Special thanks go to Drs. Helena Araújo (UERJ) and Cláudia Miranda (UNIRIO). The research was sponsored and received scholarships from CNPq, CAPES and FAPERJ.

II- Pontifícia Universidade Católica do Rio de Janeiro, Rio de Janeiro, RJ, Brazil.

Contacts: marcelo-andrade@puc-rio.br; luizccamara@hotmail.com

\begin{abstract}
How do secondary education pupils mobilize the concept of justice to deal with moral dilemmas? We have tried here to answer this research question based on empirical data and on some of Habermas's conceptions, especially the concept of procedural justice and the criteria of equality, equity, reciprocity, and role exchange. The gathering of data was made through the articulation of two methodological strategies: focal groups and the resolution of moral dilemmas involving issues of justice and human dignity. The focal groups attempted to understand the interaction between the subjects, that is, their emphasis lies on the interlocution, which turned out to be fundamental for this study of the cognitive challenges posed by the concept of justice under a discursive perspective. The moral dilemmas, in their turn, appear as hypothetical situations and, in the present investigation, they stimulate the strong involvement of the research subjects with the proposed situation. Among the possible conclusions, the research indicates that youngsters do not hesitate when challenged to take a position with respect to problems involving their beliefs and convictions. In this sense, the study reinforces the pertinence of using debates as a strategy in pedagogical practice, so that within the space and time of the school several worldviews and personal characteristics can be expressed.
\end{abstract}

\section{Keywords}

Justice - Habermas - Focal groups - Moral dilemmas Secondary school. 
Este artigo está baseado numa pesquisa que teve como objetivo verificar a maneira como os estudantes do ensino médio de uma escola pública da cidade do Rio de Janeiro operam com o conceito de justiça e como o mobilizam para lidar com dilemas morais. A referência para a análise dos dados empíricos foi a concepção de Habermas sobre justiça procedimental e seus respectivos critérios de igualdade, equidade, reciprocidade e de troca de papéis.

0 levantamento dos dados deu-se por meio da articulação de duas estratégias metodológicas complementares: (a) grupos focais e (b) resolução de dilemas morais envolvendo questões de justiça e dignidade humana. Foram realizados quatro encontros com um grupo de estudantes que se voluntariaram para a pesquisa. Os encontros ocorreram nas dependências da escola, foram registrados em áudio e tiveram a duração média de sessenta minutos. Ao todo, participaram catorze estudantes, sendo oito do sexo masculino e seis do sexo feminino, com idades entre 16 e 18 anos. A investigação foi realizada pelo Grupo de Estudos sobre Cotidiano, Educação e Culturas (GECEC), do Programa de Pós-Graduação em Educação da Pontifícia Universidade Católica do Rio de Janeiro (PUCRio), sendo que alguns pesquisadores (doutorandos, mestrandos e bolsistas de iniciação científica) trabalharam como observadores do grupo focal e outros como mediadores da discussão.

0 grupo focal, segundo Gatti (2005) e Barbour (2009), é uma técnica de pesquisa na qual se observam a discussão e a interação entre indivíduos, que podem ser pertencentes a um mesmo grupo ou possuir características comuns. Tais grupos versam sobre determinada situação ou problema que tenha alguma relação com a vivência dos sujeitos. É importante enfatizar que, para os objetivos da investigação, o grupo focal revelou-se como uma estratégia adequada, pois explicitou as convergências e as divergências de modos de pensar, bem como a maneira de os participantes reagirem e tratarem-se quando diferentes pontos de vista são confrontados, propiciando que os sujeitos da pesquisa apresentassem seus argumentos e justificativas. 0 grupo focal possibilitou, ainda, que se conhecessem as

representações, percepções, crenças, hábitos, valores, restrições, preconceitos, linguagens e simbologias prevalentes no trato de uma dada questão por pessoas que partilham alguns traços em comum. (GATTI, 2005, p. 11)

A discussão de dilemas morais em grupo foi criada por Moshe Blatt sob a orientação de Kohlberg (BIAGGIO, 2002). Essa técnica consiste em provocar conflitos cognitivos a partir do confronto entre opiniões divergentes de participantes num diálogo sobre situações problemáticas que envolvem diferenças de julgamento moral. Segundo Souza (2008), algumas orientações básicas devem ser seguidas para a aplicação dos dilemas morais: (1) os grupos devem ser formados por oito a quinze participantes; (2) os dilemas escolhidos precisam propiciar o surgimento de conflitos cognitivos; (3) os participantes devem ser orientados quanto ao que será realizado; (4) após a apresentação do dilema, é importante perguntar a cada participante sobre qual encaminhamento adotaria e sua justificativa; (5) deve-se garantir que o maior número possível de participantes vivencie o conflito cognitivo; (6) a discussão pode ser interrompida quando todas as divergências mais importantes tiverem sido cotejadas.

Nesta pesquisa, os dilemas morais continham duas partes: uma inicial, na qual se apresentava a problemática e os participantes eram convocados a posicionarem-se, oferecendo seus argumentos; depois de constatada a ausência de novos argumentos, a segunda parte do dilema era revelada e seu conteúdo procurava colocar em xeque algumas das argumentações apresentadas anteriormente pelos sujeitos da pesquisa. Assim, os participantes eram desafiados a reiniciar a discussão. No presente artigo, para a exposição dos argumentos dos estudantes, optamos por editá-los a fim de facilitar sua compreensão. 
A elaboração e a disposição da análise foram feitas de forma intercalada com as descrições de depoimentos e intervenções dos participantes, considerando-se também as observações da equipe de pesquisa.

No que se refere aos princípios éticos, vale lembrar que os sujeitos da pesquisa foram voluntários, são identificados por nomes fictícios e sua participação foi autorizada por seus responsáveis, pela direção da escola e pelas respectivas instâncias administrativas superiores. Por fim, é importante enfatizar que analisamos, a partir do referencial teórico que orienta o estudo, os raciocínios desenvolvidos durante as discussões do grupo focal, não sendo nosso objetivo avaliar o grau de maturidade moral dos estudantes, tal como se costuma fazer nos estudos sobre dilemas morais. A pesquisa buscou entender como os jovens mobilizam o conceito de justiça na resolução de dilemas morais e quais seriam seus principais argumentos para a resolução do conflito por eles enfrentado.

Tendo em vista que os dilemas têm sido utilizados com maior recorrência para entender o desenvolvimento moral de crianças, consideramos que a originalidade da investigação apresentada está, principalmente, na obtenção de resultados referentes a jovens estudantes do ensino médio de uma escola pública que atende a um público muito diversificado. A novidade dos resultados também pode ser verificada na articulação dos dilemas morais com outras estratégias metodológicas, tais como grupos focais, observações e entrevistas semiestruturadas. No entanto, devido aos limites deste artigo, apenas os grupos focais foram considerados na análise aqui destacada. Assim, esta pesquisa quer contribuir com uma fundamentação filosófica do conceito de justiça entrelaçada com dados empíricos obtidos junto aos jovens estudantes, tendo como foco o cotidiano de uma escola pública.

\section{Habermas e o conceito de justiça}

No campo da filosofia, o conceito de justiça estabelece uma diferenciação entre o que é judicialmente legal e o que é moralmente legítimo. Trata-se de uma delimitação clássica que situa as fronteiras entre o direito e a moral. É conveniente que não se perca de vista essa distinção, pois não iremos limitar o conceito de justiça ao campo da legalidade e da coerção jurídica. $\mathrm{Na}$ história da filosofia, justiça sempre significou mais do que acordos legais socialmente estabelecidos. Decorre daí uma compreensão de que existem ações que são legalmente corretas e moralmente inválidas e vice-versa.

Nessa perspectiva, optamos pelas contribuições de Habermas devido à sua concepção de justiça centrada em procedimentos ético-morais, os quais consideramos primordiais para uma fundamentação filosófica da educação e da escola como campo de pesquisa. Para Habermas (2004), o conceito de justiça, à luz de questionamentos universalistas, é retirado de seus contextos concretos e toma a forma de um procedimento que se utiliza das operações de igualdade, equidade, reciprocidade e de troca de papéis para se chegar a juízos que possam levar em conta, de forma imparcial, os interesses e os pontos de vista de todos os envolvidos. A justiça passa a ser conceituada como garantia de imparcialidade, sendo esta compreendida como a igual consideração por todos os concernidos.

A abordagem habermasiana vale-se do fundamento da moral kantiana do imperativo categórico, porém propõe que sua legitimação seja dada pelo diálogo entre os envolvidos em um possível discurso sobre os princípios que deveriam orientar as ações. Assim, a ética do discurso encontra-se inscrita nas éticas cognitivistas que defendem a ideia de que as questões práticas podem ser fruto de fundamentações racionais, em uma relação análoga às fundamentações da verdade dos enunciados teóricos sobre questões de fato (HABERMAS, 2003).

Ao corroborar o pensamento de Kant, mas propor uma superação do caráter monológico da moral, Habermas afasta-se de uma possível subjetividade dos princípios de orientação das ações humanas. 0 autor estabelece a necessidade de se pressupor um acordo entre 
todos os indivíduos possivelmente envolvidos nas consequências da aceitação de determinada norma, pois,

de acordo com a ética do Discurso, uma norma só deve pretender validez quando todos os que possam ser concernidos por ela cheguem (ou possam chegar), enquanto participantes de um discurso prático, a um acordo quanto à validade dessa norma. (HABERMAS, 2003, p. 86, grifo do autor)

É importante ressaltar que, em decorrência do estabelecimento desse princípio, segundo o qual a aceitação das normas depende do diálogo, cada indivíduo não realiza sua reflexão apenas levando em conta os interesses de todos os envolvidos, mas, além disso, entra em um processo de cooperação com os demais na busca de consenso.

Vale lembrar também que há dois pilares fundamentais para a teoria da justiça na ética do discurso: (a) o reconhecimento recíproco de todos os seres humanos como pessoas capazes de dialogar e (b) o diálogo como procedimento fundamental para definir princípios justos e decidir por ações justas.

Obviamente las condiciones en la realidad son muy diferentes a las de una situación ideal de diálogo. Pero podemos medir en qué grado nuestras sociedades son más o menos justas por lo próximo o por lo alejadas que se encuentran de realizar esa situación ideal. Así, los Estados que hacen leyes como respuestas a los intereses expresados de sus ciudadanos son más justos que los Estados que no atienden a las demandas de sus miembros, o que ni siquiera fomentan la educación entre ellos para que sean conscientes de sus propias opiniones. (SIURANA, 1998, p. 36)

Mais injusto seria o Estado, que proíbe os cidadãos de expressarem suas ideias e opiniões ou persegue-os em razão delas, considerando sempre que tais ideias não estejam em conflito com os acordos entre os implicados. Assim, Habermas trata das concepções filosóficas de justiça e admite que juristas e filósofos, influenciados pela teoria da justiça de John Rawls, reagiram surpreendentemente contra o normativismo tanto no campo da moral quanto no campo do direito. No entanto, tal reação - liberal e contratualista - não conseguiu livrar-se de um sério problema: o que fundamentaria o agir moral se o dever é visto como uma realidade impotente, sem força para orientar a ação? "Se trata aquí del viejo problema de cómo realizar el proyecto racional de una sociedad justa, que abstractamente se opone a una sociedad irracional" (HABERMAS, 1998, p. 121).

Habermas defende uma teoria da justiça que seja mais universal e ao mesmo tempo mais situada, ou, dito de outra maneira, menos liberal e mais respeitosa de outras concepções de vida política, de cultura, de sociedade e de pessoa humana.

En una sociedad pluralista la teoría de la justicia sólo podrá contar con ser aceptada si se limita a una concepción que sea postmetafísica en sentido estricto, es decir, si evita tomar partido en la disputa entre formas de vida y concepciones del mundo, que compiten unas con otras. [...] Pues bien, una teoría de la justicia cortada a la medida de las formas de vida moderna tiene que contar con una diversidad de formas de vida y planes de vida que han de coexistir dotados de unos mismos derechos; y naturalmente, sobre esas formas de vida y planes de vida cabrá esperar disenso desde la perspectiva de las diversas tradiciones y de las diversas biografías. (HABERMAS, 1998, p. 124-125)

Habermas afırma que a defesa da justiça ancorada no liberalismo político e em suas instituições deveria apresentar as razões pelas quais os demais escolheriam ser liberais. Ele defende a ideia de que, sem um liberalismo político de 
fundo, não há possibilidades institucionais para o contratualismo. No entanto, uma teoria da justiça que tenha pretensões de universalidade não deveria pertencer a um único modo de organizar a política, a economia ou a sociedade. Para ele, uma teoria de justiça não deve estar ancorada num sistema político, mas em um sistema de normas e deveres intersubjetivamente construídos, independentemente do contexto.

Convencido de que uma teoria de justiça tem mais a ver com o sistema de normas morais (deontologia) do que com um sistema político (liberalismo), Habermas (1999) apresenta as razões suficientes da autoridade do dever, ou seja, porque

formulamos proposiciones que tienen el sentido de exigir a los demás un determinado comportamiento (es decir, plantear una obligación), de comprometernos con una cierta acción (contraer una obligación), de hacer reproches a los demás o a nosotros mismos, de reconocer errores, de presentar excusas, de ofrecer una reparación etc. (p. 29)

A obrigação pressupõe o reconhecimento intersubjetivo de normas morais ou de práticas comuns que fixam, de modo convincente, para determinada comunidade, aquilo a que estão obrigados os atores, bem como o que devem esperar uns dos outros.

El concepto central de obligación se refiere no sólo al contenido de los mandamientos morales, sino al carácter peculiar de la validez del deber que se refleja también en el sentimiento de estar obligado. (HABERMAS, 1999, p. 30)

É importante ressaltar que, para a ética do discurso, as regras morais operam como autorreferenciadas. Sua força coordenadora da ação se dá em dois estágios de interação. No primeiro, as regras morais dirigem a ação social de modo imediato, na medida em que vinculam a vontade dos atores e a orientam. No segundo estágio, elas regulam as tomadas de postura crítica naqueles casos em que se dá algum tipo de conflito moral. Sendo assim,

una moral no sólo dice cómo deben comportarse los miembros de la comunidad; proporciona al tiempo razones para la resolución consensual de los conflictos de acción correspondientes. (HABERMAS, 1999, p. 30)

Segundo a ética do discurso, a formação discursiva da vontade é compreendida "como uma forma de reflexão do agir comunicativo" (HABERMAS, 2003, p. 155) que provoca uma mudança de atitude dos envolvidos, ao deixar em suspenso a validade de uma norma controversa que só merecerá ser considerada válida após tornar-se objeto de contestação entre os que a propõem e aqueles que a ela se opõem. Nesse sentido, o consenso almejado é também fruto de uma construção que apenas ocorre por uma reestruturação dos modos de pensar dos participantes do discurso prático.

Outro ponto importante é a referência à orientação para a responsabilidade com os outros, que pode ser interpretada no sentido de ações supererrogatórias. Segundo Habermas (2004), essas ações são consideradas boas e corretas, mas não podem ser exigidas de todos, devendo ser decididas em virtude de motivações individuais. Nesse sentido, as perspectivas da justiça (igualdade, equidade, reciprocidade e troca de papéis) poderiam ser compreendidas e interpretadas como acordos morais socialmente celebrados sem os quais não é possível considerar a moralidade de uma ação. Por outro lado, a preocupação e o cuidado com os outros - ações supererrogatórias - podem ser esperados e desejados, estando, entretanto, isentos de obrigatoriedade.

\section{A justiça para os jovens: entre a} imparcialidade e os afetos

0 dilema moral aplicado nesta investigação foi formulado e testado pelo grupo de pesquisa com base no trabalho de Cohen (2003), que procura discutir a relação entre dignidade 
humana e concepções de justiça. 0 dilema aqui analisado esteve composto de duas partes inter-relacionadas. A primeira parte do dilema tratava de uma situação hipotética em que vários marinheiros estão à deriva em um bote salva-vidas em alto mar após seu navio ter sofrido um acidente. 0 oficial mais graduado no bote, Capitão Pereira, deve decidir se vai embora com o bote, que já está com sua capacidade máxima de ocupação, ou se tenta salvar alguns outros marinheiros que pedem ajuda. Aos sujeitos da pesquisa, indagou-se: se você fosse o Capitão Pereira, o que você faria: iria embora salvando os tripulantes que estão no barco ou correria o risco de salvar mais vidas?

As primeiras manifestações afırmam que o capitão deveria ir embora com aqueles que já estão no bote e que não deveria arriscar a vida de alguns para salvar a de outros. As argumentações dos estudantes afırmam que o capitão não tem escolha, já que não é possível salvar todos. Assim, declara Fernando:

A tendência era afundar o bote, porque as pessoas desesperadas iam querer subir no bote, certo? Sendo que o bote está cheio, aí ia desesperar todo mundo e o bote, "bum", podia afundar, sei lá...

Entretanto, ao ser questionado pelo mediador do grupo focal sobre o que gostaria que o capitão fizesse caso estivesse na água, Fernando responde que desejaria ser resgatado, sendo sua resposta seguida de risos por parte dos demais, dada a flagrante contradição entre o que se pensa ser o certo e o que se deseja para si.

Essas primeiras respostas podem ser interpretadas como uma solução imediata, fruto de uma reflexão inicial. Os estudantes consideram a falta de alternativas um fato consumado e baseiam-se em um cálculo do menor dano possível a um maior número de envolvidos. Parece ser inquestionável para eles que é preferível salvar algumas pessoas a arriscar-se para salvar outras. Por outro lado, nesse primeiro momento do grupo focal, os estudantes parecem não se colocarem no lugar daqueles que estão no mar, posição que se altera com as risadas em reação à resposta de Fernando. Ao se sentirem diretamente atingidos pela decisão dos outros, em uma posição de dependência, o cálculo do menor dano ao maior número é desconsiderado. 0 raciocínio de Fernando, mesmo quando afırma que o Capitão Pereira deveria ir embora para salvar os que já estavam no bote, parece tomar como referência seus próprios interesses e necessidades, pois, ao ser colocado no lugar de quem iria ser deixado para trás, reconsidera o que havia afırmado. Merece destaque que, nesse momento inicial, o procedimento habermasiano de troca de papéis não acontece espontaneamente, mas, quando provocado pelo pesquisador, promove nos sujeitos de pesquisa uma mudança em sua argumentação.

Prosseguindo a discussão, Bruno sugere:

Bom, eu não iria ao encontro das pessoas lá. Por exemplo, se fosse muito perto da terra, da areia, da margem, eu iria com os sobreviventes do barco e depois eu voltaria para resgatá-los.

Aqui já há a busca por outras possibilidades. 0 raciocínio não se limita ao que é informado no dilema. Procura-se por outras possíveis soluções que conciliem a segurança daqueles que já estão a salvo e a pretensão de salvar mais vidas. A visão amplia-se e a situação de todos - os que estão no bote e os que estão no mar - parece ser levada em conta.

Quando questionados se quem estava no bote teria mais direito de sobreviver do que quem estava na água, os estudantes não se manifestam favoráveis à ideia e justificam que os primeiros deveriam ser salvos, talvez em detrimento dos outros, "porque chegaram primeiro"; "porque eles já estão dentro"; "porque eles [os que estão na água] deram mole"; porque "não tem mais espaço pra eles"; "também podem ter sido mais rápidos". Ao alerta de que, segundo essas justificativas, o capitão iria salvar os mais fortes e deixar os mais fracos morrerem, alguns estudantes afirmam que 
não é isso o que pensam. Dean sugere: "Eu acho que, pô, pegaria metade dos mais fracos e metade dos mais fortes e levaria".

Ao rejeitarem a ideia de que o direito à vida fundamenta-se em algum tipo de mérito, os estudantes parecem demonstrar que consideram este um direito universal que não está condicionado a nenhuma característica ou privilégio particular. Essa argumentação, construída entre os sujeitos de pesquisa durante a discussão do dilema, expressa a concepção de justiça procedimental de Habermas (2004), que se utiliza de um critério de igualdade compreendido a partir do reconhecimento dos mesmos direitos fundamentais (direito à vida $\mathrm{e}$ à liberdade) e do igual valor dos indivíduos. Entretanto, os estudantes necessitam justificar que, na situação imposta pelo dilema, alguns serão salvos, terão seu direito preservado, e outros não. Suas argumentações, todavia, baseiam-se no esforço e no melhor desempenho de quem conseguiu subir no bote, o que, contraditoriamente, justificaria o direito de ser salvo em razão do mérito.

Provocados pelo mediador do grupo focal - que interpreta suas explicações como baseadas no mérito -, os jovens argumentam que o capitão não poderia jogar aqueles que estão no bote ao mar para salvar outros. Assim, a complexidade do problema parece ficar mais clara. Mesmo sendo o oficial uma autoridade reconhecida, para os estudantes, ele não tem o direito de impor que alguns se sacrifiquem em benefício de outros. Tal observação expressa uma distinção importante entre as ações justas que podem ser exigidas e outras que não podem, as chamadas ações supererrogatórias, que são consideradas boas e corretas, mas que devem ser decididas apenas pelo sujeito da ação. Nesse sentido, a saída proposta por Dean, ainda que pareça equânime - salvar metade dos que conseguiram subir ao bote, merecedores pelo desempenho, e metade dos que não conseguiram, os considerados mais fracos -, impõe a alguns um sacrifício moralmente questionável, pelo fato de não ser uma decisão livre.
No primeiro momento do dilema, é possível afırmar que os estudantes, apesar de não verbalizarem explicitamente, estão operando durante todo o tempo com os critérios de uma justiça procedimental, sobretudo os critérios de igualdade e de troca de papéis. Ainda que, em alguns momentos, expressassem dúvidas e contradições, eles operaram com um conceito de igualdade ampla, não relacionado a méritos pessoais. Cabe também destacar, segundo as impressões dos observadores, o envolvimento e o cuidado que demonstraram ao ouvir e apresentar contra-argumentos às opiniões divergentes, o que indica um ambiente propício para um diálogo em condições ideais (HABERMAS, 2003).

Na segunda parte do dilema, um jovem marinheiro que estava na água aproxima-se do bote e, desesperado, tenta subir. Ao perceber o rapaz, o Capitão Pereira ordena a Antônio, o marinheiro mais próximo a ele, que o empurre e não o deixe subir, porque o bote iria afundar e todos morreriam. 0 jovem marinheiro, José, era amigo de Antônio, que agora tem de decidir se obedece à ordem do capitão ou se ajuda o amigo, colocando em risco sua vida e a de todos os outros. Aos sujeitos da pesquisa, foi feita a seguinte pergunta: o que você faria se estivesse no lugar do Antônio: obedeceria ao capitão, abandonando o amigo José, ou se arriscaria tentando salvá-lo?

Inicialmente, os estudantes afirmam que salvariam o amigo, desobedecendo à autoridade instituída e colocando a vida de todos em risco. Ao serem questionados se tal posicionamento não entrava em contradição com a postura mais consensual do momento anterior - ou seja, ir embora e salvar quem estava no bote -, eles justificam: "Porque agora é um amigo, né?"; "Porque a gente conhece, porque a gente gosta"; "Mas antes a gente estava no lugar do capitão, agora a gente está no lugar do amigo"; "E também agora é um só, não são várias pessoas gritando"; "Ué... É um risco que tem que correr, todo mundo vai morrer um dia”. No decorrer da discussão, levanta-se a possibilidade de não ser um amigo que está tentando subir no bote, mas sim um familiar, ao 
que Fernando, categórico, diz: "Pô, aí se por um amigo eu jogaria o capitão! Imagina?! Jogo todo o resto por minha família".

Até então, a discussão vinha mantendo um distanciamento, uma postura de impessoalidade e imparcialidade. A universalidade do direito à vida tinha sido mantida sem questionamentos e exceções, mesmo quando apareceu a questão do merecimento ou desempenho daqueles que conseguiram chegar ao bote supostamente por suas habilidades. Na discussão anterior, os estudantes reconheceram que todos possuíam igual direito de sobreviver, embora a situação em que se encontravam não possibilitasse isso. No entanto, ao ser introduzido um elemento de pessoalidade - um dos sobreviventes é identificado e tem uma relação afetiva com o agente que precisa decidir -, o cálculo do menor dano possível a um maior número de pessoas é imediatamente deixado de lado. Ao que parece, inicialmente, o amigo possui mais direito de viver do que os demais, pois vale a pena arriscar a vida de todos para salvá-lo. Merece ser destacado que essa posição é mais incisiva quando, no lugar de um amigo, é um familiar que depende da decisão.

As justificativas passaram a basear-se, então, na relação de proximidade afetiva e no fato de haver apenas uma pessoa a ser salva, o que supostamente diminuiria o risco de afundar o bote. Se interpretarmos os novos argumentos a partir das perspectivas da justiça procedimental (igualdade, equidade, reciprocidade e troca de papéis), eles agora expressam uma noção de igualdade restrita àqueles considerados de uma mesma categoria (amigos e familiares), sendo aceito um tratamento desigual entre pessoas de categorias diferentes (amigos e familiares versus desconhecidos). Essa diferença torna-se mais explícita no desenvolvimento da discussão. Ao serem questionados sobre o que fariam se outro marinheiro estivesse tentando salvar um amigo que não conhecessem, duas posições diferentes são apresentadas. Fernando diz: "Aí fica complicado. Eu até empurrava o outro para dentro da água também”. Joey contemporiza:
“Se [o marinheiro] estivesse tentando salvar ele [o amigo], eu ajudaria, mas se ele não estivesse tentando salvar, sei lá”.

Pode-se afirmar que ambos os posicionamentos desconsideram a universalidade do direito à vida e mantêm a referência nas relações pessoais e afetivas. A posição de Fernando pode ser considerada mais restrita, pois aceita que se corram riscos para salvar a vida de um amigo ou parente, mas apenas se este for de seu círculo de relações. Parece não ser o valor da amizade ou do parentesco em geral o que é utilizado como critério para se abrir uma exceção e arriscar-se, mas sim o valor específico de suas próprias relações de amizade e parentesco. A posição de Joey pode ser interpretada como uma valorização da amizade e do parentesco de forma generalizada, expressando um raciocínio que parece utilizar-se do critério de troca de papéis da justiça procedimental habermasiana, pois aceita que qualquer um teria o direito de tentar salvar um amigo, mesmo que para ele trate-se de um desconhecido. Merece destaque na fala de Joey o fato de ele não afirmar a iniciativa para salvar um desconhecido, mas apenas para ajudar caso se tratasse de um amigo de alguém que já estivesse no bote. 0 raciocínio de Fernando não considera a igualdade como abrangendo pessoas de círculos mais amplos; nele também estão ausentes as operações de equidade e de troca de papéis, segundo os critérios de Habermas (2004). Já o raciocínio de Joey, por reconhecer que qualquer um poderia querer salvar um amigo, expressa uma coordenação entre as operações de reciprocidade e igualdade, bem como uma avaliação da situação não apenas de seu ponto de vista, mas a partir da perspectiva de outra pessoa.

Diante do impasse, um dos estudantes aponta como solução consultar os demais marinheiros: "Se fosse eu, tentava ajudar ele [o amigo], se também todo mundo concordasse". Porém, ao ser questionado sobre o que faria se os outros não concordassem, diz que salvaria assim mesmo e "ia ver no que ia dar". Na proposta de uma consulta aos outros marinheiros, 
dois aspectos merecem ser destacados: o questionamento público da autoridade do capitão e a ampliação do fórum de decisão, que deixaria de ser individual e passaria a ser coletivo. Esse raciocínio parece utilizar-se também da operação de troca de papéis que considera a necessidade de levar em conta os pontos de vista e os interesses de todos os que estariam correndo o risco. Todavia, não se pode deixar de reconhecer os limites do posicionamento desse estudante, que afirma que salvaria seu amigo mesmo sem a concordância dos demais, o que talvez indique um momento de transição e incerteza em suas convicções morais.

Outra saída é proposta por Renato, que considera o risco que todos estão correndo. Ele sugere, então, que o melhor seria jogar-se ao mar e ficar na mesma situação do amigo: "Provavelmente eu ia me jogar também, aí ia ter que morrer os dois". E justifica: "Pelo menos morreu tentando ajudar". Greg, por sua vez, sugere que se troque de lugar com o amigo, pulando ao mar e deixando que ele suba no bote, ou, como alternativa nessa mesma direção, que seja feito um revezamento: "Vai revezando, pô, vai cada um, um pouquinho. Um pouquinho no barco. Pula, aí vai o outro...”. Uma razão apresentada para trocar de lugar com o amigo, segundo Dean, seria transferir o peso da decisão para os outros: "Daria meu lugar para ele, aí eles, os que estavam lá no barco, ficariam com peso na consciência”. Porém, outros estudantes questionam sua posição. "Eu acho que eles não ficariam com peso na consciência não”, diz Elena; "Seria a troca de um desconhecido por outro desconhecido, eles nem iam ligar”, ao que Dean responde: "Pelo menos meu amigo ia ficar com peso na consciência”.

As saídas apresentadas que consideram a possibilidade de partilhar sua situação ou de trocar de lugar com quem está no mar podem ser interpretadas como indicações de uma visão que considera não apenas a perspectiva da justiça, mas também a do cuidado e da preocupação com os outros. Pondera-se que não seria justo colocar em risco a vida de todos os que estão no bote para salvar uma pessoa, mesmo que seja alguém com quem se tenha uma relação de afeto. Ao mesmo tempo, não se esquece dessa relação e propõe-se uma alternativa que oferece risco e sacrifício apenas para si mesmo. Esse é um tipo de sacrifício que não pode ser exigido, mas apenas assumido em virtude de motivações próprias, como um exemplo de ações supererrogatórias (HABERMAS, 2004).

A razão apresentada por Dean - deixar os outros ou o próprio amigo com peso na consciência - poderia ser interpretada como uma negação do autossacrifício, com base na ideia de que seria um sofrimento menor morrer do que ficar com peso na consciência, ou como uma fuga do peso de tomar uma decisão difícil. Merece destaque o fato de seu argumento não ter sido acompanhado pelos demais, mas sim questionado, o que demonstra a percepção de uma contradição entre dispor-se a sacrificar-se por alguém e, ao mesmo tempo, querer impingir-lhe um sofrimento (peso na consciência).

Pode-se considerar que a proposta do revezamento significa uma busca de alternativas que consideram os interesses e as responsabilidades dos envolvidos, embora restritos ao círculo de amizade. Ao propor o revezamento, o raciocínio de Greg considera as operações de reciprocidade e de troca de papéis compreendidas segundo a concepção de justiça procedimental habermasiana, pois os envolvidos terão a mesma oportunidade de contribuir e receber os benefícios da solução proposta.

Outros questionamentos e ressalvas são apresentados. Elena pergunta a um dos rapazes o que ele faria caso se jogasse ao mar com a intenção de partilhar o infortúnio do amigo e este subisse no bote: "Aí eu matava ele. Por que eu fiquei deixando de salvar minha vida por causa dele”. Jéssica argumenta: "Qual motivo você teria de resgatar o seu amigo? Não seria viver com ele? [...] Então, se você se jogasse não ia viver com ele". Para Dean, a opinião do outro deve ser levada em conta em sua decisão de sacrificar-se: "Isso não depende só de você, 
também da pessoa que está sendo salva. Pois será que ela quer que você se mate por ela? Será que ela vai deixar você ficar lá?". Nesse debate, ao argumentar que consultaria o amigo sobre a possibilidade de sacrificar-se por ele, Dean está propondo uma operação segundo o critério de troca de papéis. Tal raciocínio parece considerar igualmente o próprio desejo de sacrificar-se e os sentimentos que o outro vivenciaria ao sobreviver graças a esse sacrifício. Poder-se-ia ainda arriscar a interpretação de que a preocupação com o outro vai além de sua sobrevivência, atentando também para seu estado emocional futuro, o que poderia sinalizar uma concepção moral orientada não apenas pelos critérios de justiça, mas pelo cuidado com os outros.

Jogar o capitão ao mar e trocá-lo pelo amigo é uma opção que surge na discussão. Matheus sugere: "Eu ia derrubar o capitão e ia pegar o Antônio"; "Está todo mundo com raiva do capitão aqui”, afırma Elena; "É que aí ele ia voltar para o cargueiro e ajudar o pessoal que ele deixou lá", completa Jéssica. Essa proposta é também questionada por outros participantes, que alegam que se poderia piorar a situação, argumentando que "a gente é marinheiro, tem que ter comandante, alguém que... [seja] um líder". Como contra-argumento, outros afirmam que, apesar de o capitão ser mais experiente, todos no bote são marinheiros e têm noção sobre o que fazer. Ao serem questionados se o jogariam ao mar mesmo sabendo que, ao tomar sua decisão, ele pensou em salvá-los, objetam alegando que ele não pensou no grupo, mas em si mesmo: "Não, ele não pensou em salvar, nós corremos para o bote. Ele foi porque ele quis", defende Matheus; "Eu acho que ele não tentou salvar todo mundo, ele só pensou nele mesmo, pensou em si”, afirma Renato. Nessa argumentação, Matheus e Renato deixam transparecer que, se estivessem no lugar do capitão, teriam tomado decisões a partir de interesses meramente pessoais e não como um líder responsável pelos demais.

A solução que propõe trocar o capitão pelo amigo questiona sua posição de autoridade e considera que ele possui menos direito à vida do que os demais. A decisão do capitão de seguir em frente, deixando os outros para trás, e sua ordem para que o marinheiro Antônio não permitisse que o amigo subisse ao bote não são avaliadas, nesse momento, como tendo sido efetuadas em razão do coletivo, mas sim como fruto de resolução pessoal e interesse egoísta. De modo idêntico à argumentação que sugere uma consulta aos demais, o que motiva a proposta de jogá-lo ao mar parece ser o interesse particular em virtude de uma relação de amizade com aquele que corre perigo e precisa ser salvo. Há aqui uma dificuldade de se colocar no lugar de alguém que possui responsabilidade pelo coletivo, que deve decidir levando em conta várias circunstâncias e não apenas suas preferências pessoais. A esse raciocínio também se aplica a observação, feita anteriormente, sobre a impossibilidade moral de se exigir que alguém se sacrifique para que outros sejam beneficiados. Ao discordarem do descarte do capitão, os outros estudantes, todavia, não o fazem a partir do valor universal da vida e do direito do capitão a sobreviver, mas com um argumento que considera sua utilidade para o grupo. 0 capitão é considerado importante, ao que parece, apenas para que continue coordenando o salvamento de todos que estão no bote, não porque possui uma dignidade em si mesmo.

Ao serem questionados se faria diferença em sua decisão se o amigo fosse jovem, idoso ou tivesse filhos, a maioria dos estudantes posiciona-se afirmando que não ou que naquele momento não pensariam nisso. Ao declararam que não consideram relevante a idade do amigo que precisa de ajuda ou o fato de outras pessoas dependerem dele, eles parecem demonstrar que o único critério para se abrir uma exceção e arriscar a vida de muitos em favor de um é, novamente, a relação de amizade e de parentesco.

A discussão no segundo momento do dilema coloca os estudantes em uma posição de proximidade pessoal e afetiva com os envolvidos em suas decisões, o que pareceu provocar um conflito cognitivo ainda maior do que no 
momento anterior. Durante a discussão dessa parte do dilema, houve muitos argumentos e contra-argumentos entre os critérios da justiça procedimental habermasiana e as justificativas que levam em conta preferências pessoais, sentimentos e possibilidade de autossacrifício. Seguindo a metodologia de grupo focal, a discussão do dilema foi interrompida sem que os estudantes chegassem a um acordo sobre qual seria a decisão a ser tomada. Optou-se pelo fim do debate por dois motivos centrais: primeiro, por não serem apresentadas novas argumentações; segundo, porque o objetivo de pesquisa era examinar a interlocução de argumentos entre os sujeitos e não exatamente a construção de consensos.

\section{Conclusões}

Acreditamos que a investigação propiciou-nos algumas conclusões possíveis. A primeira diz respeito à adequação da metodologia empreendida para a obtenção dos dados empíricos. Os grupos focais têm sido cada vez mais utilizados em pesquisas no campo educacional (GATTI, 2005). Diferentemente das entrevistas coletivas, eles buscam entender a interação entre os sujeitos, ou seja, a ênfase está na interlocução, o que se apresentou como fundamental para o estudo dos desafıos cognitivos sobre o conceito de justiça numa perspectiva discursiva. Os dilemas morais, por sua vez, apesar de se apresentarem como situações hipotéticas, propiciaram um alto envolvimento dos sujeitos da pesquisa com a situação proposta. Ainda que poucos jovens, segundo seus relatos, tivessem tido a real experiência de estar numa embarcação, todos assumiram a situação como possível e argumentaram a partir dela, demonstrando que estavam vivenciando a experiência narrada. Os dilemas despertaram, entre os depoentes, a criatividade na busca de justificativas e a argumentação acalorada sobre seus pontos de vista.

A segunda conclusão foi a pertinência da concepção de justiça procedimental como referencial teórico. Os critérios habermasia- nos de troca de papéis e da busca de igualdade como perspectiva de validade foram os aspectos que mais puderam ser percebidos entre os interlocutores, o que demonstra a vitalidade desse arcabouço teórico para pesquisas que queiram entender a construção e o desenvolvimento do juízo moral entre nossos jovens. Vale destacar que os critérios da reciprocidade e da equidade foram pouco observados, o que pode revelar algo sobre os sujeitos da pesquisa, sobre o desenvolvimento moral nessa faixa etária ou mesmo sobre o tipo de dilema que utilizamos, o qual talvez não tenha propiciado a mobilização explícita de tais procedimentos.

Uma terceira conclusão surge a partir dos argumentos desenvolvidos pelos sujeitos da pesquisa no encaminhamento dos dilemas morais. Foi possível observar que os estudantes, de maneira geral, fundamentaram seus argumentos a partir de duas orientações básicas: uma baseada em uma concepção de justiça procedimental e outra apoiada nas relações afetivas. A primeira desenvolve-se principalmente a partir de algumas operações de igualdade e de troca de papéis, como já indicado. A segunda apoia-se fundamentalmente em relações de proximidade, sobretudo na amizade e no parentesco. A presença dessas duas orientações aponta para a necessidade de ampliação das referências sobre a construção do juízo moral entre os jovens para além do desenvolvimento cognitivo. A investigação serviu-nos de alerta para a importância de se tomar como referência para a compreensão do pensamento moral de jovens e adolescentes outras abordagens que levem em conta não apenas procedimentos racionais, mas também o papel dos afetos na construção da moralidade dos jovens. Aqui, novas perspectivas para a continuidade da pesquisa ficam apontadas.

0 trabalho de observação dos grupos focais e a análise dos depoimentos demonstraram que os jovens participantes não hesitaram quando desafiados a posicionarem-se em relação a problemas que envolvem suas crenças e convicções. Essa postura pode ser interpretada como sinalizadora da pertinência 
e da importância que a temática abordada pela pesquisa possui para eles, ou seja, tais sujeitos estão empenhados em entender o que é justiça, o que é uma decisão justa, e a optar por ela. Contrariando o senso comum e algumas queixas recorrentes de professores, a qualidade da participação dos interlocutores demonstrou que os sujeitos de pesquisa, embora possam ser considerados muito jovens, possuem maturidade e capacidade de ouvir e respeitar as opiniões de seus pares, mesmo quando estas são divergentes, e estão interessados em resolver os problemas que lhes são apresentados. Essa quarta conclusão também reforça a pertinência de se utilizar o debate - argumentos, contra-argumentos, construção de consenso, valorização de dissensos e conflitos cognitivos - como uma estratégia válida para a prática pedagógica. Assim, a pesquisa ajudou-nos no objetivo de apresentar uma fundamentação ético-filosófica para a prática pedagógica com base na perspectiva habermasiana.

A quinta conclusão merece atenção especial, pois se trata do questionamento - por parte dos estudantes em vários momentos da discussão - da figura de autoridade representada pelo Capitão Pereira. Tal questionamento talvez indique que os jovens pesquisados desconfiam da capacidade dos adultos em assumir sua responsabilidade na resolução de problemas e conflitos; pode sinalizar também uma postura de autono- mia perante as questões que lhes são apresentadas. Ambas as possibilidades de interpretação colocam aos profissionais da educação o desafio de planejarem práticas e construírem espaços de troca a partir dos quais o diálogo sobre as crenças e as convicções presentes no cotidiano escolar possa ser garantido. 0 espaço e o tempo da escola podem ser pensados de forma que as diversas visões de mundo e as características pessoais tenham a possibilidade de expressar-se e de serem conhecidas e reconhecidas como manifestações legítimas das várias identidades e dos valores que estão em processo de constituição.

Por fim, partindo do pressuposto de que são as práticas discursivas (HABERMAS, 2003, 2004) que constituem e intermedeiam a construção do conhecimento, enfatizamos que os diversos saberes presentes no cotidiano escolar podem ser questionados e convertidos em objeto de investigação, em discursos argumentativos entre professores e estudantes em situações de diálogo Do mesmo modo, as regras e normas que orientam as relações e o funcionamento da instituição podem ser compreendidas como produção coletiva e, consequentemente, como responsabilidade de todos. Talvez aí esteja nosso principal achado de pesquisa e também nossa maior aposta para uma fundamentação ético-filosófica no campo educacional que tenha a concepção de justiça procedimental como um de seus pilares. 


\section{Referências}

BARBOUR, Rosaline. Grupos focais. Porto Alegre: Artmed, 2009.

BIAGGI0, Angela Maria Brasil. Lawrence Kohlberg: ética e educação moral. São Paulo: Moderna, 2002.

COHEN, Martin. 101 dilemas éticos. Madrid: Alianza, 2003.

GATTI, Bernadete Angelina. Grupo focal na pesquisa em ciências sociais e humanas. Brasília: Liber Livro, 2005.

HABERMAS, Jürgen. Facticidad y validez: sobre el derecho y el Estado democrático de derecho en términos de teoría del discurso. Madrid: Trotta, 1998.

La inclusión del otro: estudios de teoría política. Barcelona: Paidós, 1999.

Consciência moral e agir comunicativo. Rio de Janeiro: Tempo Brasileiro, 2003.

Verdade e justificação: ensaios filosóficos. São Paulo: Loyola, 2004.

SIURANA, Juan Carlos. Historia de la idea de justicia. In: CORTINA, Adela et al. Educar en la justicia. Valencia: Generalitat Valenciana, 1998. p. 23-52.

SOUZA, Luciana Karine. 0 debate de dilemas morais na universidade. Psicologia Escolar e Educacional, Maringá, v. 12, n. 1, p. 169-183, jun. 2008.

Recebido em: 09.05.2012

Aprovado em: 21.08.2012

Marcelo Andrade é licenciado em Filosofia, mestre em Educação e doutor em Ciências Humanas pela Pontifícia Universidade Católica do Rio de Janeiro (PUC-Rio). Cumpriu o Programa de Doutorado Parcial no Exterior na Universitat de València, Espanha. É professor do quadro principal do Departamento de Educação da PUC-Rio, no qual coordena 0 Grupo de Estudos sobre Cotidiano, Educação e Culturas (GECEC).

Luiz Câmara possui graduação em Filosofia pela Universidade Federal do Rio de Janeiro (UFRJ), especialização em Docência do Ensino Superior pela Universidade Candido Mendes (UCAM) e mestrado em Educação pela Pontifícia Universidade Católica do Rio de Janeiro (PUC-Rio). É doutorando em Educação pela PUC-Rio, com inserção no Grupo de Estudos sobre o Cotidiano, Educação e Culturas. 